\title{
Disability Studies as a Source of Critical Inquiry for the Field of Assistive Technology \\ Jennifer Mankoff \\ $\mathrm{HCl}$ Institute \\ Carnegie Mellon University \\ jmankoff@cs.cmu.edu

\author{
Gillian R. Hayes \\ Department of Informatics \\ University of California, Irvine \\ gillianrh@ics.uci.edu
}

\author{
Devva Kasnitz \\ Devvaco Consulting \& \\ Society for Disability Studies \\ devva@earthlink.net
}

\begin{abstract}
Disability studies and assistive technology are two related fields that have long shared common goals-understanding the experience of disability and identifying and addressing relevant issues. Despite these common goals, there are some important differences in what professionals in these fields consider problems, perhaps related to the lack of connection between the fields. To help bridge this gap, we review some of the key literature in disability studies. We present case studies of two research projects in assistive technology and discuss how the field of disability studies influenced that work, led us to identify new or different problems relevant to the field of assistive technology, and helped us to think in new ways about the research process and its impact on the experiences of individuals who live with disability. We also discuss how the field of disability studies has influenced our teaching and highlight some of the key publications and publication venues from which our community may want to draw more deeply in the future.
\end{abstract}

\section{Categories and Subject Descriptors}

H.1.2 [User/Machine Systems]: human factors

\section{General Terms \\ Human Factors}

\section{Keywords}

Disability studies, assistive technology

\section{INTRODUCTION}

Disability studies is the interdisciplinary study of disability in society [40]. Like other areas of critical inquiry, the field of disability studies explicitly delves into the underlying premises of work that relates to the experience of people considered "disabled." Similar to other fields concerned with minority groups (feminist studies, African American studies, etc.), it also is driven by the goal of giving people a voice in academic work that may otherwise be done about them but not necessarily with them. Disability studies constitutes an ongoing attempt to define the rhetoric, language, methods, and purpose of academic work related to the personal and social experience of disability [32].

The field of disability studies has been in existence for at least three decades, with the founding of the Society for Disability Studies in 1982. This scholarly community continually contributes to the understanding of and engagement with the experience of disability. However, disability studies is generally not visible in the assistive technology literature, as defined by

Permission to make digital or hard copies of all or part of this work for personal or classroom use is granted without fee provided that copies are not made or distributed for profit or commercial advantage and that copies bear this notice and the full citation on the first page. To copy otherwise, or republish, to post on servers or to redistribute to lists, requires prior specific permission and/or a fee.

ASSETS'10, October 25-27, 2010, Orlando, Florida, USA.

Copyright 2010 ACM 978-1-60558-881-0/10/10...\$10.00. the ACM ASSETS conference, the Transactions on Accessible Computing journal, RESNA, and so on. Considering the interest by disability studies researchers in technological solutions and the interest in tackling issues relevant to disability studies among assistive technology researchers, a more in depth look at the connections between these fields is warranted.

In this paper, we explore some of the disability studies literature relevant to assistive technology. This literature has proven both thought-provoking and useful in our own work. It has led to new problem areas and broadened our thinking about the research process and outcomes in light of the lived experiences of individuals with disability. Also, it has helped us to reflect on our own experiences with disability in relation to our work.

This paper is organized as follows: (1) background on disability studies (2) examples of our work and how a disability studies perspective has and could be impactful in those works, and (3) some core reading with which assistive technology researchers should be familiar, and a discussion of opportunities for and benefits of cross-fertilization between the assistive technologies and disability studies research communities.

\section{BACKGROUND ON DISABILITY STUDIES}

Much can be done to alleviate the difficulties associated with impairment and disability through social action, reducing bias and discrimination, inclusive design, and so on. However, critical inquiry into the rhetoric and actions surrounding disability demonstrates how both non-disabled academics and society in general sometimes make problematic assumptions about the lived experience of disability, such as the assumption that disability is always a burden or something in need of assistance. Critiques of work concerned with "helping" the disabled call into question the premise that "helping" the disabled is the right starting place. A better understanding of what constitutes a problem from a disability studies perspective can help to enrich existing research and illuminate new areas of inquiry. As an example, an understanding of the socio-cultural models of disability (discussed below) can lead to the idea that the person designing a piece of software is, in some sense, defining who is disabled with respect to that software.

In this section, we review some core ideas from the disability studies literature. Disability studies, or more specifically critical disability studies [49] is a field of critical inquiry focused on the lived experience of disability, and the societal, medical, and intellectual policies and rhetoric concerned with disability. At times, disability studies can be a harsh critic of some approaches to assistive technology. However, this literature can also help our community to focus on the most impactful problems, suggest new directions that support critical thinking about our work, and add to and inform the ways in which we collaborate with and give the subjects of our work a voice in what we do. 


\subsection{An Historical Overview}

The social and intellectual origins of the field of disability studies include scholarly work, the disability rights movements, and policy and legislative activism. Following the independent living movement in the U.S. in 1979, DeJong declared a paradigmatic shift from a "rehabilitation" or "individual" model of disability to an "independent living" model [12]. At the same time in the U.K., disability rights activists and academics focused on a shift from a "medical" to a "social" model [5]. The medical model is instrumental, focused on the individual and their physical condition and limitations; social models propose that cultural and societal factors (e.g., inclusion and exclusion, availability of services) are more central to determining which groups of people experience disability and how.

Despite international interest, for purposes of brevity, we focus on disability studies development within the United States. This began with the disability rights movement, which focused on addressing societal problems faced by groups of people experiencing disability through a combination of personal empowerment and legally mandated integration into the "mainstream of American society" [72]. A basic tenet of this movement is that while impairment is seen as a physical or biological condition of a person (meaning that a limb, organ, or function of the body is somehow negatively different), disability is a form of exclusion propagated by a society that marginalizes or discriminates against people who are seen as being impaired. For example, deafness is an impairment (hearing is lacking). However, in a town where everyone communicates through sign language [18], deafness may not be perceived as a disability. The disability rights movement uses different approaches in different contexts to reduce marginalization and give people power over their own lives, individually and collectively. Much has been accomplished, as evidenced by legislation such as the Rehabilitation Act of 1974 and the Americans with Disabilities Act. However, compliance with this Act continues to be a challenge, and various Supreme Court rulings have weakened the resulting legislation [68].

A defining feature of American disability studies is its focus on representation, language, and action in the world as subjects of study by social science and the humanities. Text and image may be seen as a form of social action (or oppression), as in a newspaper article that discusses disability as "nothing other than a devalued lack." [69] Furthermore, among research and activist communities and the public, there is a debate surrounding how to describe, or self-describe the people who are our focus. "Person first language" (e.g., "a person with a disability") has become the U.S, standard. However, because it objectifies disability as a thing residing in the person, some choose to use "disabled people" (the U.K. standard) to stress that disability is a devaluing social process imposed upon, but not an inherent part of, the person. There are theoretical, political, and personal reasons authors may want to choose one over the other, both interchangeably, or simply talk about "people who experience disability" $[40,55,68]$. To demonstrate the complexity of this issue, many groups have recently reclaimed disability or an impairment descriptor as a positive assertion of identity and a new "normal": "Deaf person," "Little person," "Autistic person," and even "Mad person" are the most common examples [40]. Issues such as the context of use may also affect what term is chosen (for example using people first labels in an advocacy setting but experiential labels in the classroom).
Regardless of what label is used, the context and purpose of labeling can lead to negative consequences [16].

\subsection{The Medical and Social Models}

From a disability studies perspective, the question of language goes beyond labeling and ties into the very heart of how we define disability. Just as labels may have negative consequences, so may the model through which disability is viewed and understood. Analytical consideration of varied models of disability, then, is helpful in understanding how our research and technologies fit into this space.

Designers of assistive technologies may find the medical model pragmatically useful, because it focuses on the physical and functional limitations a person may demonstrate. These represent actionable challenges and present opportunities for measurable results. Adaptations that improve typing speed, screen readers, and personal augmentative communication devices all flow naturally from a medical model of disability. However, "if the medical model prevails, a person with an impairment might, justifiably, be asked to forgo his/her autonomy forever..." [72].

In contrast, when social models are more dominant, attempts to "fix" disability naturally turn outward toward problems of access, oppression, and activism. Medical models can be characterized by a focus on fixing an impairment; social models may lead to a shift from "cure to care" [74], in which "patients," not clinicians, become the leaders in managing their conditions [8], and societal change is also part of the solution. The social model and the associated independent living movement promotes a belief that self-advocacy and peer support are first steps to full participation in society, citizenship, and leadership development [31]. These concepts can be an important driver for the adoption of assistive technologies.

However, social models also have limitations. For example, if disability is truly defined only by society, the experience of impairment is to some extent invalidated, and the possibility of the need for medical treatment sidelined [54]. Further, both social and medical models ignore that impairment too is a social construction, worthy of sociological study $[56,61]$. Some social and medical models rest uncomfortably on an assumption that the goal is normality (that is, the elimination of disability) [54]. This undercuts the potential positive aspects of the disability experience, such as a common community and culture and pride in one's individuality.

A third approach, a post-modern model, privileges each individual's unique lived experience, complete with the complexity and nuance of everyday life. Disability, illness, impairment, functional limitation, and bodily anomaly are separate but complementary issues, and successful assistive technologies must account for all of these perspectives [58]. Because some conditions may require medical attention and involve serious secondary problems, it is worth understanding (and perhaps improving upon) the medical model of "impairment." At the same time, social models of disability should not be abandoned, as they reduce the risk of "blame the victim" social policies [54]. Finally, a cultural understanding of disability is needed to avoid the mistaken assumption that the ultimate goal is "normality." Physical pain may best be understood within medical and phenomenological models; social suffering within a combination of critical and cultural models; structural inequity within ecological models, and so on. 
Thus, assistive technology researchers can benefit from greater understanding of the literature from this complex and vibrant area of creative thought.

\section{CASE STUDIES}

To illustrate the value of bringing critical thinking and interdisciplinary participatory methods from disability studies into assistive technology, we present case studies from our own work in two areas. The first case study relates to autism. We discuss some challenges in balancing the goals of educational institutions, parents, and children and how technologies developed to support this population can either reify their diminished status or empower them. The second case study relates to computer accessibility. We discuss the implications of social models of disability for the work done by designers of technology, and the challenges inherent in inclusive or universal design. We then turn to projects focused on simplifying design, prototyping, and testing.

\subsection{Autism and Educational Technology}

In this section, we explore the tensions surrounding design and use of educational and assistive technologies for children who experience autism when considered from a cultural, institutional, and disability rights viewpoint. This discussion follows on from the results of two qualitative studies [21, 23, 25]. Both studies focus on understanding the care of children with autism, and one focuses on the experience of children with severe behavior disorders and school-based care providers during school hours.

Our first study focused on current practices, needs, and privacy concerns of the various children and care providers [25]. The data consisted of audio and video recordings and observer notes. Interview participants included two school professionals, six professional therapists, three parents, and two part-time therapists. We conducted 144 hours of participant observation.

It was during this initial study that we began to notice the impacts of the "medical model" for autism and the overarching rehabilitation perspective in treating these children. As described in the introduction, the medical or individual model stems from an underlying belief "that disability results from an individual person's physical or mental illness" [38]. It often emphasizes a kind of "helplessness" [33]. This model is prevalent in both medical training and the literature of fundraising foundations, and is often espoused by the groups dedicating significant time, money, and resources to helping individuals "affected by autism." Probably the most visibly criticized of these non-profit organizations is AutismSpeaks, about whom numerous campaigns within the disability rights community have been launched. These efforts include a petition "AutismSpeaks doesn't speak for me"1, innumerable blog entries, and even a movie shown at the Sundance Film Festival (http://www.sundancechannel.com/ films/500317006/).

Despite public criticism of AutismSpeaks and other similar organizations, there are also supporters who note these organizations raise substantial funds for research and advocacy ${ }^{2}$. For a concerned family member, the medical model may be all they can initially absorb as they process their children's situations.

\footnotetext{
${ }^{1}$ http://www.autism-hub.co.uk/autism-speaks-dont-speak-forme/index.php

${ }^{2}$ AutismSpeaks provided funding for the work described
}

When faced with the experience of severe autism, which might include the inability to independently use the toilet or severe discomfort and pain at various external stimuli (e.g., lights or noise), concerned parents might simultaneously love their children and reasonably and desperately wish for a cure, an orientation more aligned with medical models. The quest for a cure can be a source of hope for struggling parents while creating the potential for hurting other members of the community:

It is not possible to separate the autism from the person. Therefore, when parents say, 'I wish my child did not have autism,' what they're really saying is, 'I wish the autistic child I have did not exist and I had a different (non-autistic) child instead.' Read that again. This is what we hear when you mourn over our existence. This is what we hear when you pray for a cure. This is what we know, when you tell us of your fondest hopes and dreams for us: that your greatest wish is that one day we will cease to be, and strangers you can love will move in behind our faces. [64]

Wanting to explore explicitly the ways in which various models of disability play out in schools, we expanded our prior work by spending three years working with teachers, staff, and students from a school focused on students with both severe behavior disorders and cognitive disabilities. The results presented stem from analysis of empirical data from approximately 300 hours of observation at this school. During this period, we developed a new record-keeping technology to support teachers and aides in understanding the children in their classrooms [23]. The four teachers and ten aides participating in the trial were interviewed weekly during a five-month trial of this technology. Interviews were also conducted with the school social worker, principal, lead teachers, behavioral analysts, and speech therapists.

\subsubsection{Cultural Production in Special Education}

Special education is often focused on creation of students who can one day be "main-streamed"- that is to say, creating students who understand the implicit and explicit rules of our non-autistic culture well enough to function appropriately within them. The socially and culturally constructed category of individuals with autism includes people who demonstrate enough specific observable differences in social behavior from the norm to qualify them according to a series of quantitative empirically based diagnostic measures. Thus, in autism classrooms, cultural transmission, "the process of passing on culturally relevant knowledge, skills, attitudes, and values from person to person or from culture to culture" becomes explicit [39]. Teachers and staff use a variety of methods for teaching students "how to think, act, and feel" [66] like people who are not autistic.

This cultural transmission becomes so explicit in autism classrooms - as opposed to the implicit but still ever-present role of cultural transmission in "regular" education-because for children with autism, cultural transmission through traditional means can be particularly challenging. In describing the interactions of a family affected by Asperger's Syndrome, Sacks reports the family members "know the rules and conventions of "normal'" but are unable to internalize these, to understand them at the level that those without such disabilities interpret the culture around them [59]. Instead they learned "to ape human behavior" without fully understanding what is behind the customs [59].

Similarly, a wide variety of interventions have been devised to support development of communication skills for individuals experiencing autism. Tools ranging from visual communication 
[9] to social stories to encourage more nuanced interactions have been developed over many years and provide the groundwork for development of assistive technologies, including in part our own work [24, 27]. However, these interventions and tools all take an "ableist" view that asserts that people with autism must be made capable of communicating like neurotypical (NT) people. This approach ignores the view that individuals with autism may actually view NTs as demanding, over-communicative, and even wasteful in their communication $[52,1]$. The goal then, perhaps should not always be to teach people with autism to "engage in NT-style small talk" [63], but rather to support NTs in communicating with individuals who might

\begin{abstract}
much rather have someone walk up to me and tell me some interesting fact I hadn't known before about grasshoppers, or helicopters, or forensic dentistry, than have someone approach me uninvited to tell me something I'm perfectly aware of, such as the fact that it's a sunny or a rainy day. If you're going to interrupt my train of thought and place demands on my cognitive processing to focus on you and comprehend what you're saying, at least say something that's intellectually engaging! [63]
\end{abstract}

By acknowledging the existence of a disability culture-or more specifically an autism culture-we engage with a broader view of communication itself. This bottom-up cultural construction of autism broadens the scope of what we might deem assistive technologies and tools for augmentative communication. The design space of assistive technologies for autism, as with other communication barriers, can and should include technologies that involve both interlocutors in the communication process. This moves beyond a medical model focused on "fixing" a person and recognizes that any communication should include adjustments by everyone. For example, in addition to an augmentative communication device that helps autistic children to approach their peers in "socially appropriate" ways, it could be helpful to create tools that help NT children to approach their autistic peers in "autistically appropriate" ways.

\subsubsection{Education as a Structural Institution}

Examination of the structural forces inherent to both education and its view of disability provides another view of the interplay between assistive technology and disability for the autism community. Government agencies and non-profit organizations have responded to the growing "epidemic" of autism through campaigns to "Learn the Signs, Act Early" (http://www.cdc.gov/ncbddd/actearly) diagnose children with autism earlier, and generally to provide better monitoring and epidemiological surveillance of this growing population. The result is a new form of "governmentality," [14] in which programs designed to protect the rights of this population subject them to a rational, normalizing lens that lacks an understanding of their diversity, culture, or personal identity. For example, during early diagnostic sessions, "experts" demonstrably privilege standardized tests such as the IQ score and the Assessment of Basic Language and Learning SkillsRevised (ABLLS-R) as evidence, over the opinions of those closest to the child. Reams of parent and teacher generated narrative are often discarded as anecdotal. Dimitriadis and Carlson describe the process by which "special education" students become so labeled:

This process draws together professional educators, psychologists, and doctors in diagnosing the learning "disorders" of individual students and then prescribing a "treatment." The effect is that students are brought together under a totalizing and regulatory gaze, and teachers' role is reconstituted around testing, record-keeping, monitoring, and surveillance. [13]

These efforts stem from legitimate concern about the growing rates of autism diagnoses and the potential burden placed on society in terms of financial obligations of the public schools and healthcare system, a change in availability of workers, and simply concern for the general welfare of the citizens of various nations. Following along these lines, we have been involved in efforts to develop technologies to support earlier diagnoses of autism [34, 35] and other early childhood disability [22].

After the initial diagnostic and labeling period, students are subject to further measurement throughout their schooling. In the 1980's and 1990's in most of the industrialized world a trend towards concepts of "outcomes" and "performance indicators" began to appear in education. Such movements have generally fallen under the categories of outcomes-based education (OBE) and standards-based education $[65,17,20]$.

In special education in the U.S., OBE leads to Individual Education Plans (IEP), negotiated for each student on a regular schedule (typically once a year). The emphasis on measurement and accountability has placed a substantial burden of documentation on individual classroom staff. Inspired by this problem with record-keeping, we sought to use capture and access technologies to automate some of the documentation needs and make visualizations and summaries of data more readily available [23]. Our early design and formative work was focused largely on the views of care providers of children with severe autism. These providers were heavily invested in the medical model and evidence-based practices in schools. However, upon deploying the technology in schools at the same time as we encountered the disability studies literature, we began to view these technologies in a different light. Our focus had been on empowerment of the teachers (its own challenge in a system that inherently privileges administration and legislation), and we began instead to see a path for empowering individual students in the classroom.

\subsection{Designing for Accessibility}

One goal of assistive technologies is to solve access problems across a broad swath of interfaces. An example is screen readers, which render interactive systems in audio, making it possible to use a computer without being able to see the screen. However, any solution is constrained by the broader context in which it operates. For example, screen readers only work well if web pages are designed with them in mind. Thus, in our second case study, we examine the role of disability studies in technology accessibility.

From a disability studies perspective, technology design is inherent to who has "access" and who experiences barriers. A badly designed interface might unnecessarily create a population of users who are "disabled" with respect to that system (those for whom design problems are barriers to use). Thus, designers have a responsibility not to marginalize atypical users.

Augmentations designed to increase access, such as voice recognition, may also be appropriated by "able users" for other purposes. The potential for augmentations designed for a specific population to be useful for the benefit of all in part drives the universal usability movement. Universal usability 
focuses on enabling not just access to technology, but success (access + usability) by all, regardless of technology, ability, or skill [62]. This goal has led to many improvements over current designs, often by adding flexibility to underlying infrastructure (such as allowing fonts to be resized in web pages). Among those who are most different from each other, needs may differ to the point that they are in opposition to each other, and one solution cannot be used by everyone. An approach that works to address this issue is inclusive design [53], which extends user centered design to include minority groups.

Limited training and availability of tools for designers and developers can hinder progress towards universal usability and inclusive design. Most user interface and web designers have had little or no exposure to accessibility, or at best have read something along the lines of the World Wide Web Consortium's (W3C) Web Accessibility Guidelines (http://www.w3.org/ $\mathrm{WAI} /$ ). In addition, even a well meaning, well trained professional who wishes to explore the accessibility of a product in a user centered fashion will face substantial challenges.

Good interface design benefits from early and frequent evaluation of ideas, but it can be difficult to bring in disabled participants for these types of studies [10]. It is often very difficult to recruit more than a few disabled people to test a new design. Given the heterogeneity of the population, even if this sample were larger, it is unlikely to be representative in the traditional usability testing vernacular. Furthermore, the time required to recruit, run a study, and evaluate the results can grow immensely depending on the challenges of a particular population. It may be difficult to gather as much data as is needed due to issues of fatigue and reduced speed from accessibility problems. Also, it is difficult-if not impossible - to replicate the custom set up that makes potential participants effective in controlling their home computers, necessitating home visits or limiting the quality of data [10]. Finally, technology designed by someone who is not experienced in making it accessible may be so inaccessible that it is a waste of everyone's time to test it with its target population before basic issues are addressed.

One of the most universally used technologies is the web, and as a result its accessibility has received a great deal of attention. In part due to legal pressure, the $\mathrm{W} 3 \mathrm{C}$ has developed guidelines to enhance web accessibility for people with disabilities. Although broad, these guidelines are most specific and actionable for those experiencing blindness. For example, for individuals whose input is constrained to a very low bandwidth (a small number of characters per minute), the guidelines are missing potentially helpful strategies for increasing web accessibility [47]. Problematically, the guidelines are often interpreted with respect to specific web pages by automated tools that are not able to find all of the most important problems [48].

Although it would ultimately be preferable to test accessibility of web pages with their target users, in practice, this is almost never done. We accepted the inherent difficulties of "doing it right" and developed best practice guidelines with what was feasible. We compared the performance of different approaches to testing the accessibility of web pages [48]. These included automated tools that highlight guideline violations but do not involve users, designers with minimal training (having read a summary of the $\mathrm{W} 3 \mathrm{C}$ guidelines), designers with access to a screen reader who could both view and "hear" a page to better understand the experience of someone using a screen reader, and remote users who were blind and could test the pages at home. The designers with the screen readers were consistently high performers in comparison to the other techniques. However, we did not provide enough structure for the remote users in terms of how rigorous to be, making them less effective.

In a separate thread of research, we began to explore tools that, like the screen reader, could give designers increased intuition about the effect of different impairments on the experience of using their designs. We developed a tool that could simulate a range of impairments. Simulation has been used in the past and continues to be used to promote disability awareness via exercises such as riding a wheelchair or wearing a blindfold. However, simulation treads a fine line between helping someone to improve their understanding of disability and reinforcing problematic opinions [36]. In many cases, simulations give the uninitiated an overly negative view of disability as they fail to navigate their experience successfully.

Simulation has also been used in computer access settings. An example is our EASE project [45]. EASE extends a virtual network computing client (VNC), technology that allows one computer to remotely view and control another, which sends all its input and output events to the client. We extended a client to modify those event streams to simulate motor and vision impairments. For example, based on past work demonstrating the types of errors associated with motor impairments, our client could make the mouse perform as if someone with a motor impairment were controlling it. Similarly, it could modify the output stream to simulate visual blind spots or focus problems. Our validation showed that EASE's motor impairment simulation led to predictable text entry speeds with word prediction.

Simulation represents a low cost and quick way to get feedback in the computer access domain [26]. It can help to ensure that when true usability/accessibility testing is done with disabled participants, the interface is not so bad that it is a waste of everyone's time. However, computer simulation suffers from similar problems to simulation exercises: it lacks the true experience, likes, dislikes, work arounds, thoughts and feelings of participants: the soul of the experience. Additionally, computer simulation may not be accurate. Finally, "bypassing their opinions for the sake of convenience would be disrespectful to a population" that when included experienced "the first opportunity that they had to express their opinions to people who were interested in listening" [6]. Despite these issues, simulation has been applied to problems of augmentative and alternative communication [26], web accessibility [67], and education (http://www.webaim.org includes scripted simulations of screen reader use, low vision, magnification, and distractibility).

We argue there are alternatives. One alternative is to engage one or a few disabled individuals in the process in a deep way over time. This approach of bringing in people from the "target population" as a fully engaged equal participants throughout the design process is heralded by proponents of the Participatory Design movement within HCI [51], and has at times been usefully applied to assistive technology as well (e.g., $[50,73])$. Although only one or a few representatives of a broad and diverse population, these participants can help to shed light on things that may be outside the researcher's ken, they may be more familiar with the experience of others with similar conditions, and can help to identify situations where more data is needed. Additionally, their participation can help to surface tacit false assumptions, which are self evident to the representatives but may not be obvious to designers. 
A second alternative includes gathering a corpus of data that can be used to test hypotheses rather than attempting to simulate experience (e.g., [29]). A data corpus can be designed to represent a much wider range of individuals, will by definition include examples of their real day to day experiences, and is easy to test against (just like a simulation). Unfortunately, the "soul" (and interpretive faculties) of a population are missing in this method, just as with simulation.

\section{CONNECTING DISABILITY STUDIES AND ASSISTIVE TECHNOLOGY RESEARCH}

The goal of this paper is to encourage the continued development of deep theoretical and scholarly connections between the assistive technologies and disability studies communities. Disability studies scholars draw methods from critical theory [49], anthropology [37], discourse analysis [30], historical analysis [72], and other social and behavioral sciences with a focus on inclusion and engagement with disabled researchers through techniques such as participatory action research. Many of these methods (though not all) are shared by the assistive technology research community, including participatory research (e.g., [50, 73]). However, an inclusive approach can be made a more substantial part of our scholarship through activities like co-authoring and co-editing articles with disabled individuals and inclusion of disabled individuals as advisors [71]. True "participatory" research includes the collaboration of the "subject" in all aspects of research, including problem definition, methods, data collection, analysis, publication, and dissemination [4].

Although disability studies has not been prominent in the assistive technology literature, assistive technology has been a subject of inquiry within the disability studies literature. For example, Living in the State of Stuck [60] describes the relationship of assistive technology to the lives of a diverse set of people experiencing disability. Other examples of critical explorations of assistive technology include Tusler's studies of the corporate drivers leading to accessible technologies [70] and Guo's study of the social impact of the Internet on the disability community [19]. Litvak and Enders describe how these kinds of studies can highlight how impairment, environment, and technology interact in a triangular model to remove or create barriers [41]. For example, disability studies can help occupational therapists understand their role as gatekeepers to people receiving or learning to use assistive technology [44]. Another area of exploration is the impact of assistive technologies on the current form of assistance most available to individuals experiencing disability: human assistants. Rather than replace human assistance, assistive technology changes the human assistance needed [41]. To be of service, an assistant must know the technologies the person they are assisting uses, which are often complex. If the disabled person uses intricate word processing software, so must the assistant. The issues of choosing, programming, maintaining, and repairing these devices is central to their ultimate adoption and use [11].

\subsection{Rethinking Assistive Technology Research in Light of Disability Studies}

The drive to solve real world problems, to help people in need, and to use computation for societal good [7, 28] is to be applauded. We frequently engage in activities with these goals as well as the common ableist rhetoric that surrounds them. However, through our exposure to and engagement with the disability studies literature, we have come to a more nuanced understanding of these efforts. A project may have technical merit, and may solve observable problems, but still fail to address the complex interplay of issues at work and to take the most appropriate approach to addressing those issues. Furthermore, it is important to acknowledge that there may not even be a "right" problem to tackle or a "right" approach to take. Flexibility cannot be overvalued.

A general misunderstanding of the perspective of individuals with disability is inherently intertwined with attempts to "do good" within both academic and non-academic efforts. As one recent example of this clash, Kras described the "Ransom Note Affair" in which "ransom notes" from Autism, Asperger's Syndrome, Bulimia, and other "childhood psychiatric disorders" were used in a public awareness campaign [38]:

Autism: We have your son.

We will make sure he will not be able to care for himself or interact socially as long as he lives.

This is only the beginning.

The response to these ads from the neurodiversity movement was heated and demonstrated the "evolution away from a paternalistic models of advocacy to one of self-advocacy" [38]. Bloggers, community leaders, and the heads of a variety of foundations and activism groups wrote public letters to the campaign requesting its end and created their own publics service campaign with ransom notes holding a variety of messages, such as:

\section{To NYU Child Study Center.}

We have your disdain. We have your pity. We have your disrespect. We have had enough of these already.

End the Ransom Notes Campaign.

Respect Autistic Voices Now

"Bev" 2007

Following these responses, national and international media coverage, and heated debates in the press and in person, the campaign was eventually ended. We must, as a community of designers and advocates in our own way, work to ensure that our quest to help does not result in these kinds of unintended consequences.

Although we have used disability studies in some ways to critique the assistive technology research and policies in which we and others are involved, the neurodiversity and disability rights movements actually bring to the forefront many opportunities for expanded research in these areas.

For example, through blogs, online communities like the Autistic Self Advocacy Network, and virtual communities in places such as Second Life, the visibility and influence of these movements have grown in response to current events. Likewise, the accessibility of cell phones is hotly debated on websites, listservs, and blogs [57]; new open source communities, such as Inclusive Android, are developing around open platforms that can be made accessible by the public if not by manufacturers. As researchers focused on technologies that support and enable individuals and the disability community, we have the opportunity to connect with these groups and these movements. Open areas for research include the use of technology to support empowerment and understanding and inter/multi-disciplinary work that connects issues such as language and culture to the use of technology. Even in our more traditional work (e.g., the 
development of augmentative communication devices) we have found it useful and important to engage a disability studies perspective to avoid well-meaning errors.

\subsection{The Role of Disability Studies in Teaching}

Although this paper is primarily research focused and driven by the need to improve our empirical and theoretical understandings of disability in relation to assistive technology, we have also worked to incorporate some of this material into our teaching. From an educational perspective, students learning about assistive technologies, in addition to works previously cited, should be exposed to key readings including the Encyclopedia of Disability [2] and Living in the State of Stuck [60]. They should also familiarize themselves with participatory work such as $[4,15,42]$. Finally, they should be familiar with journals in both areas and conferences such as the annual conference of the Society for Disability Studies. Students should familiarize themselves with topic-specific work. For example, if working with individuals with cognitive impairments, a good read is [43]. Those working in the area of hearing impairments might benefit from watching the documentary "Sound and Fury" [3].

Additionally, we recommend to those teaching assistive technology classes or more focused courses on designing for specific disability barriers to take a participatory approach with the communities they wish to serve. Guest speakers who selfidentify with disability and even discussions by students in the class who have close experience with disability or chronic illness can rewarding ways to encourage students to explicitly engage their biases, assumptions, and (mis)conceptions about disability. Service learning, such as mini internships with relevant community organizations are valuable because students assume the role of apprentice or assistant as opposed to problem solver. This can help orient students in a new way to the issues with which they are trying to grapple [46].

\section{CONCLUSION}

By exploring the individual, cultural, societal, and theoretical foundations of the concept of assistance and the design of disability-related technologies, we can expand our view of assistive technologies and their place in the complex world of disability. In this paper, we have reexamined technology design and evaluation through two case studies that outline some of the issues brought up by engagement with disability studies. A broader, more nuanced view of impairment and disability highlights new needs surrounding technologies and educational and support systems.

Each of us took a different route to these conclusions. Two of us identify as disabled. Two of us design technology. We all publish in communities ranging from HCI, to disability studies, to anthropology. We have all encountered situations in which someone who immediately experiences the problem we want to "fix" critiqued a project that seemed to have self-evident benefits. We have also all been inspired to work more closely with the populations we mean to serve. When possible, we include people with disabilities on our design teams and include them as well as care providers in the work of scoping the research project and publishing the results. Finally, we focus on inclusion of people with disability in the education of our students. Earlier and more substantive collaboration has proven rewarding in terms of our scholarship and our lives and can enrich the work of disability studies and the entire assistive technologies community.

\section{ACKNOWLEDGMENTS}

This work was supported in part by NSF grants IIS-0916459, EEEC-540865, CAREER-0846063 and by generous funding from Google and AutismSpeaks.

\section{REFERENCES}

1. Adam, P. (n.d.). Small Talk. Wellsphere. $\mathrm{http} / / /$ www.wellsphere.com/autism-autism-spectrum-article/smalltal/590422. Retrieved April 23, 2010.

2. Albrecht, G. (Ed.). (2006). Encyclopedia of Disability. Thousand Oaks: Sage.

3. Aronson, J. (2000). Sound and Fury.

4. Balcazar, F. E., Keys, c. B., Kaplan, D. L., \& Suarez-Balcazar, Y. (1998). Participatory action research and people with disabilities: Principles and challenges. Canadian Journal of Rehabilitation , 12 (2), 105-112.

5. Barnes, C., \& Mercer, G. Disability (key concepts). Cambridge: Polity.

6. Bedrosian, J. L. (1995). Limitations in the use of nondisabled subjects in AAC research. Augmentative and Alternative Communication, 11, 6-10.

7. Buckley, M., Nordlinger, J., \& Subramanian, D. (2008). Socially relevant computing. SIGCSE'08, (pp. 347-351).

8. Clark, N. M. (2003). Management of chronic disease by patients. Annual Review of Public Health, 24, 289-313.

9. Cohen, M. J., \& Sloan, D. L. (2007). Visual Supports for People with Autism: A Guide for Parents and Professionals. . U.S.A.: Woodbine House.

10. Coyne, K. P., \& Nielsen, J. (2001 October). How to conduct usability evaluations for accessibility: Methodology guidelines for testing websites and intranets with users who use assistive technology. Nielsen Norman Group.

11. Dawe, M. (2006). Desperately seeking simplicity: how young adults with cognitive disabilities and their families adopt assistive technologies. CHI'06, (pp. 1143-1152)

12. DeJong, G. (1979). Independent living: From social movement to analytic paradigm. Archives of Physical Med. Rehab. , 60, 435-446.

13. Dimitriadis, G., \& Carlson, D. (2006). Promises to Keep: Cultural Studies, Democratic Education, and Public LIfe. New York: RoutledgeFalmer.

14. Foucault, M. (1979). On Governmentality. Ideology and Consciousness, 6, 5-22.

15. French, S. (1994). Researching disability. In S. French (Ed.), On Equal Terms: Working with Disabled People (pp. 136-147). Oxford: Butterworth-Heinemann.

16. Gallagher, J. J. (1976). The sacred and profane uses of labeling. Mental Retardation, 14 (6), 3-7.

17. Glatthorn, A. A. (1993). Outcome Based Education: Reform and the Curriculum Process. Journal of Curriculum and Supervision, 8 (4), 354-63.

18. Groce, N. E. (1985). Everyone Here Spoke Sign Language: Hereditory Deafness on Martha's Vineyard. Harvard University Press.

19. Guo, B. (2005). Building Social Capital: A Study of the Online Disability Community. Disability Studies Quarterly, 25 (2).

20. Hargreaves, A., \& Moore, S. (2000). Educational Outcomes, Modern and Postmodern Interpretations: response to Smyth and Dow. British Journal of Sociology of Education, 21 (1), 27-42.

21. Hayes, G. R., \& Abowd, G. D. (2006). Tensions in designing capture technologies for an evidence-based care community. Proc. CHI'06, (pp. 937-946).

22. Hayes, G. R., Cheng, K., Hirano, S., Park, S., Gravem, D., Rich, J., Cooper, D. (2010). FitBaby: Using observations of daily living to improve the health of preterm infants and their caregivers. Proc. WISH'10.

23. Hayes, G. R., Gardere, L., Abowd, G. D., \& Truong, K. N. (2008). CareLog: A selective archiving tool for behavior management in schools. Proc. CHI'08, (pp. 685-694). 
24. Hayes, G. R., Hirano, S. H., Marcu, G., Monibi, M., Nguyen, D. H., \& Yeganyan, M. T. (2010). Interactive visual supports for Children with autism. Personal and Ubiquitous Computing, To Appear.

25. Hayes, G. R., Kientz, G. A., Truong, K. N., White, D. R., Abowd, G. D., \& Pering, T. (2004). Designing capture applications to support the education of children with Autism. Proc. Ubicomp'04, (pp. 161178).

26. Higginbotham, D. J. (1995). The use of non-disabled sub jects in AAC research: Confessions of a research infidel. Augmentative and Alternative Communication, 11, 2-5.

27. Hirano, S., Yeganyan, M., Marcu, G., Nguyen, D., Boyd, L.A., Hayes, G.R. vSked: Evaluation of a System to Support Classroom Activities for Children with Autism. Proc CHI 2010. April 12-15, 2010. Atlanta GA USA, 1633-1642.

28. Hochheiser, H., \& Lazar, J. (2007). HCI and social issues: A framework for engagement. International Journal of Human Computer Interaction, 23 (3), 339-374.

29. Hurst, A., Mankoff, J., \& Hudson, S. E. (2008). Understanding pointing problems in real world computing environments. Proc. ASSETS'08, (pp. 43-50).

30. Kang, J.-G. (2009). A Teacher's Deconstruction of Disability: A Discourse Analysis. Disability Studies Quarterly, 29 (1).

31. Kasnitz, D. (2001). Life event histories of independent living. In M. Priestly (Ed.), Disability and the Life Course (pp. 67-79). Cambridge: Cambirdge University Press.

32. Kasnitz, D. \& Shuttleworth, R.P. (2001). Anthropology and Disability Studies. In Rogers, L.J. \& Swadener, B.B. (Eds.), Semiotics and dis/ability: interrogating categories of difference. New York: State University of New York Press.

33. Kemp, E. (1981). Aiding the disabled: No pity, please. New York Times.

34. Kientz, J. A., \& Abowd, G. D. (2009). KidCam: Toward an Effective Technology for the Capture of Children's Moments of Interest. Pervasive '09, (pp. 115-132).

35. Kientz, J. A., Arriaga, R. I., \& Abowd, G. D. (2009). Baby steps: evaluation of a system to support record-keeping for parents of young children. Proc. CHI'09, (pp. 1713-1722).

36. Kiger, G. (1992). Disability simulations: Logical, methodological and ethical issues. Disability \& Society, 7 (1), 71-78.

37. Klotz, J. (2003). The culture concept: anthropology, disability studies and intellectual disability. In Disability Studies and Research Institute (DSaRI) Symposium. Sydney, Australia.

38. Kras, J. F. (2010). The 'Ransom Notes' Affair: When the Neurodiversity Movement Came of Age. Disability Studies Quarterly, 30 (1).

39. LinguaLinks Library, Version 4.0. (1999). SIL International.

40. Linton, S. (1998). Claiming Disability: Knowledge and Identity. New York: NYU Press.

41. Litvak, S., \& Enders, A. (2001). The interface between individuals and environments. In G. L. Albrecht, K. D. Seelman, \& M. Bury (Eds.), Handbook of Disability Studies (pp. 711-733). Sage.

42. Lloyd, M., Preston-Shoot, M., Temple, B., \& with Wuu, R. (1996). Whose project is it anyway? Sharing and sahping the research and development agenda. Disability and society, 11 (3), 301-315.

43. Mactavish, J., Mahon, M., \& Lutfiyya, Z. (2000). I can speak for myself: Involving individuals with intellectual disabilities as research participants. Mental Retardation, 38, 216-227.

44. Magasi, S. (2008). Disability studies in practice: A work in progress. Topics in Stroke Rehabilitation, 15 (6), 611-17.

45. Mankoff, J. C., Fait, H., \& Juang, R. (2005). Evaluating accessibility through simulating the experiences of users with vision or motor impairments. IBM Systems Journal , 44 (3), 505-518.

46. Mankoff, J. (2006). Case study of Service-Learning for HCI: Practical guidelines for successful integration. CHI'06 Extended Abstracts, Experience Report, (pp. 201-206).

47. Mankoff, J., Dey, A. K., Batra, U., \& Moore, M. (2002). Web Accessibility for Low Bandwidth Input. ASSETS'02, (pp. 17-24).

48. Mankoff, J., Fait, H., \& Tran, T. (2005). Is your web page accessible?: a comparative study of methods for assessing web page accessibility for the blind. $\mathrm{CHI}^{\prime} 05$, (pp. 41-50).
49. Meekosha, H., \& Shuttleworth, R. (n.d.). What's so 'critical' about critical disability studies? Australian Journal of Human Rights , In Press.

50. Moffatt, K., McGrenere, J., Purves, B., \& Klawe, M. (2004). The participatory design of a sound and image enhanced daily planner for people with aphasia. Proc. $\mathrm{CHI}^{\prime} 04$, (pp. 407-414).

51. Muller, M. J., \& Kuhn, S. (1993). Participatory design. Communications of the ACM, 36 (6), pp. 24-28.

52. muskie. (n.d.). Institute for the Study of the Neurologically Typical. http://isnt.autistics.org. Retrieved April 23, 2010.

53. Newell, A. F., \& Gregor, P. (2000). "User Sensitive Inclusive Design" - in search of a new paradigm. Proc. CUU'00, (pp. 39-44).

54. Oliver, M. (1996). Chapter 3: Defining Impairment and Disability: Issues at Stake. In C. Barnes, \& G. Mercer (Eds.), Exploring the Divide (pp. 29-54). Leeds: The Disability Press.

55. Oliver, M. (1994). Politics and language: Understanding the disability discourse. Unit in Disability Studies Programme . Dept. of Psychotherapy, University of Sheffield.

56. Paterson, K., \& Hughes, B. (1999). Disability studies and phenomenology: The carnal politics of everyday life. Disability \& Society, 14 (5), 597-610.

57. Pedlow, R., Kasnitz, D., \& Shuttleworth, R. (n.d.). Barriers to the adoption of cell phones for older people with impairments in the USA: Results from an expert review and field study. Journal of Technology and Disability, To Appear.

58. Pinder, R. (1996). Sick-but-fit or Fit-but-sick? Ambiguity and Identity in the Workplace. In C. Barnes, \& G. Mercer (Eds.), Exploring the Divide (pp. 135-156). Leeds: The Disability Press.

59. Sacks, O. (1995). An anthropologist on Mars. In An anthropologist on Mars: Seven paradoxical tales (pp. 233-282). London: Picador.

60. Scherer, M. J. (2000). Living in the State of Stuck: How Assistive Technology Impacts the Lives of People with Disabilities. Brookline Books.

61. Shakespeare, T. (2006). Disability Rights and Wrongs. Abingdon: Routledge.

62. Shneiderman, B. (2000). Universal usability. Communications of the ACM , 43 (5), pp. 84-91.

63. Sinclair, J. (2010). Cultural Commentary: Being Autistic Together. Disability Studies Quarterly, 30 (1).

64. Sinclair, J. (1993). Don't Mourn For Us. Our Voice, 1 (3).

65. Smyth, J., \& Dow, A. (1998). What's Wrong with Outcomes? Spotter planes, action plans and steerage of the educational workplace. British J. of Sociology of Education, 19 (3), 291-303.

66. Spindler, G., \& Spindler, L. (2000). Fifty Years of Anthropology and Education: 1950-2000. Mahwah, NJ: Lawrence Erlbaum.

67. Takagi, H., Asakawa, C., Fukuda, K., \& Maeda, J. (2004). Accessibility Designer: Visualizing Usability for the Blind. Proc. ASSETS'04, (pp. 177-184).

68. Thomas, C. (2007). Sociologies of Disability and Illness: Contested Ideas in Disability Studies and Medical Sociology. Palgrave McMilian.

69. Titchkosky, T. (2005). Clenched Subjectivity: Disability, Women, and Medical Discourse. Disability Studies Quarterly, 25 (3).

70. Tusler, A. (2005). How to Make Technology Work: A Study of Best Practices in United States Electronic and Information Technology Companies. Disability Studies Quarterly, 25 (2).

71. Walmsley, J. (1997). Including People with Learning Difficulties: Theory and Practice. In L. B. Oliver (Ed.), Disability Studies: Past Present and Future (pp. 62-77). Leeds: The Disability Press.

72. Winter, J. A. (2003). The Development of the Disability Rights Movement as a Social Problem Solver. Disability Studies Quarterly, 23 (1), 33-61.

73. Wu, M., Richards, B., \& Baecker, R. (2004). Participatory design with Individuals who have Amnesia. Proc. Participatory Design Conference 2004, (pp. 214-223).

74. Zola, K. I. (1983). Developing New Self-Images and Interdependence. In N. Crewe, I. K. Zola, \& \&. Associates (Eds.), Independent Living for Physically Disabled People (pp. 49-59). San Francisco, Washington, London: Jossey-Bass. 